\title{
PENGARUH AIR COOLER TERHADAP TEMPERATUR MESIN PADA KAWASAKI DTRACKER 150
}

FANNI FATTAH \& DHIKI WISNU WARDANA

Program Studi Teknik Mesin, Fakultas Teknik, Universitas Muhammadiyah Tangerang

Jl. Perintis Kemerdekaan I/33 Cikokol-Tangerang

E-mail: vanfattah@gt-tires.com

\begin{abstract}
ABSTRAK
Sebuah inovasi dilakukan dengan cara membuat alat pendingin untuk mesin Kawasaki Dtracker 150, bertujuan mengurangi panas pada mesin dengan menggunakan teknologi yang sederhana. Hal ini bertujuan agar Mesin Kawasaki Dtracker 150 yang tidak dilengkapi dengan sistem pendingin dan juga dengan kecepatan standar agar mampu bersaing dengan sepeda motor terbaru dalam hal kecepatan dan akselerasi. Pembuatan alat pendingin pada Kawasaki Dtracker 150 dibuat ketika Kawasaki Dtracker 150 yang telah di modifikasi mesinya sering terjadi piston rusak. Dampak kerusakan tersebut pasti sangat merugikan dan dari kejadian ini muncul gagasan bahwa bagaimana sebuah mesin harus dalam temperatur standar. Penelitian menggunakan metode design of experiment untuk mendapatkan design yang paling optimum. Desain dibuat menggunakan perangkat lunak solidwork dalam hal ini bertujuan untuk mengurangi resiko kegagalan. Setelah desain selesai baru akan dibuat secara real pada Kawasaki Dtracker 150 dan menghasilkan hasil yang memuaskan. Penggunaan alat pendingin untuk mesin motor Kawasaki Dtracker 150 sangat efektif dan mampu mengurangi panas mesin hingga $22 \%$
\end{abstract}

Kata Kunci: Panas, Oil Cooler, Pendingin, Dtracker 150

\section{PENDAHULUAN}

Semua mesin sepeda motor sudah dilengkapi dengan sistem pendingin, akan tetapi belum bisa mengatasi panasnya mesin sepeda motor tersebut. Hal ini dikarenakan mesin sepeda motor masih menggunakan sistem pendingin dengan mengandalkan udara yang berhembus ke sirip - sirip blok mesin, terutama sepeda motor lama. (Saputro, 2016) Untuk mengatasi hal tersebut perlu ditambahkan sebuah sistem pendingin mesin seperti penambahan pendingin oli (oil cooler) atau radiator pada motor tersebut.

Oil cooler tersebut berfungsi untuk mendinginkan temperatur oli sekaligus mendinginkan temperatur mesin. Cara kerjanya, oli mesin yang disalurkan dari pompa oli mengalir terlebih dulu ke filter oli, lalu masuk ke jalur baru yang dibuat kemudian ke oil cooler. Setelah oil cooler oli mengalami proses pendinginan, setelah itu baru masuk lagi keruang bakar. (Apinino, 2017).

Dari berbagai aspek dan pertimbangan di atas, kemudian diajukan suatu Perancangan Oil Cooler Untuk Mesin Kawasaki Dtracker 150 dan Pengaruhnya Terhadap Temperatur Mesin yang berbasis pada sistem pendingin mesin dengan mengembangkan fitur oil cooler yang selanjutnya akan digambar terlebih dahulu skema aliran oli dan baru akan di aplikasikan langsung secara real ke mesin motor Kawasaki Dtracker 150 sehingga akan dapat dibuat secara bagus dan dapat digunakan secara efektif.

\section{A. Sistem pendingin pada Kendaraan}

Sistem pendingin oli (oil cooler system) adalah suatu sistem yang berfungsi untuk menurunkan temperatur minyak pelumas yang terdapat di dalam lower tank radiator. Selama mesin bekerja, bagian mesin akan menjadi panas. Karena minyak pelumas lebih rendah temperaturnya disamping melumasi, juga berfungsi sebagai fluida pendingin, yang menyerap panas dari bagian mesin tadi. Hal itu menyebabkan temperatur minyak pelumas menjadi naik, karena sebelum masuk kembali ke dalam bak minyak pelumas (karter oli), minyak pelumas itu harus didinginkan terlebih dahulu sebelum dialirkan kembali ke seluruh bagian mesin. Selain itu kelebihan sistem pendingin ini bisa menjangkau seluruh bagian mesin. Bahkan menembus celah yang paling terkecil pada mesin. Sebagai contoh celah antara piston dengan dinding silinder. Dalam sistem pendingin ini, piston pun ikut didinginkan. (Saputra, 2017)

Selain digunakan pada sepeda motor, oil cooler juga digunakan pada mesin diesel. Di mesin diesel sendiri oil cooler berguna untuk menjaga 
level temperatur oli engine. Temperatur oli engine tidak boleh melebihi $120^{\circ} \mathrm{C}$. Sehubungan dengan adanya friksi dan beban panas yang terjadi pada oli di dalam high perfomance engine, heavy duty diesel engine, oli temperatur akan naik sehingga perlu didinginkan secara terus menerus agar temperatur oli sesuai dengan temperatur kerja oli. (Irfan, 2007).

Engine oil cooler terdiri dari sebuah metal housing yang memiliki sekumpulan tube tembaga yang mana terpisah oleh susunan sekat (buffle). Coolant engine mengalir didalam tube tube dan oli engine yang panas mengalir di sekitar bagian luar dari tube.

Oil cooler mengurangi temperatur maksimum dari oli engine dan juga mempercepat tercapainya temperatur kerja engine dengan cara mensirkulasi oli engine sampai mencapai kerja maksimum. (Yuwono, 2013)

\section{B. Prinsip Kerja Oil Cooler}

Prinsip kerja oil coller adalah oli mesin yang dialirkan oleh oil pump (pompa oli) disaring terlebih dahulu ke oil filter (filter oli). Kemudian akan dialirkan ke dalam oil cooler dan dinginkan dengan menggunakan udara yang berhembus saat motor sedang melaju di jalan raya, selanjutnya oli yang telah didinginkan ini dialirkan menuju kisi - kisi oil cooler, dari kisi kisi oil cooler akan dialirkan ke seluruh komponen mesin bergerak, dan terakhir semua oli tersebut akan jatuh ke dalam bak oli.

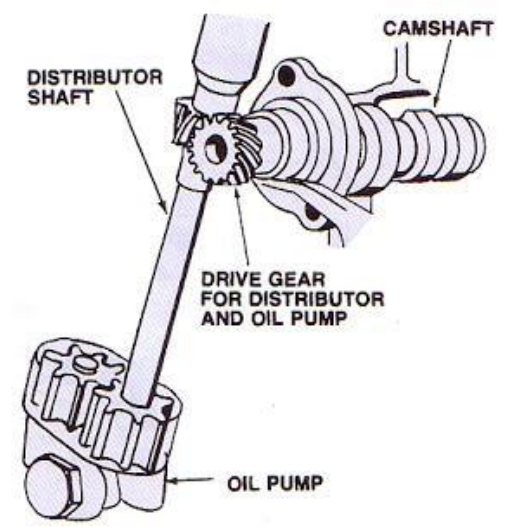

Gambar1
Ditinjau dari cara kerja pompanya. Oil cooler dapat dibedakan biasanya menggunakan pompa oli type gear.

Pompa oli tipe gear berfungsi dengan cara berputarnya 2 gigi (drive gear dan driven gear) di dalam rumah pompa oli, oli ditarik dari bak oli melalui lubang inlet dan disalurkan keseluruh bagian mesin melalui lubang outlet.

\section{METODOLOGI PENELITIAN}

\section{A. Metode Penelitian}

Metode penelitian yang digunakan adalah metode rekayasa (suatu kegiatan rancang) yang tidak rutin, sehingga di dalamnya terdapat kontribusi baru, baik dalam bentuk proses maupun produk/prototype. Adapun Urut-urutan penelitian di jabarkan dalam illustrasi di bawah.

\section{B. Lokasi Penelitian}

Penelitian ini dilakukan di Ruku ROR Bumi Indah. Adapun lokasi tersebut merupakan kediaman dari penulis.

\section{Alat dan Bahan}

Agar penelitian dapat dilakukan dengan baik, maka dalam hal ini dibutuhkan beberapa alat dan bahan yang dapat mendukung jalannya penelitian. Adapun alat dan bahan yang digunakan adalah sebagai berikut :

1) Alat

- Satu set kunci pas

- Baut Nepel

- Satu set kunci ring

- Selang

- Obeng

- Oil Cooler

- Thermometer Infrared

- Part Pemisah Jalur Oli pada Bak Filter

2) Bahan

- Bahan Bakar Pertamax

- Oli mesin 5W-15

- Sepeda motor Kawasaki Dtracker tahun 2010.

\section{Alur Penelitian}

Diagram alir dari metode penelitian ini mengikuti gambar di bawah: 


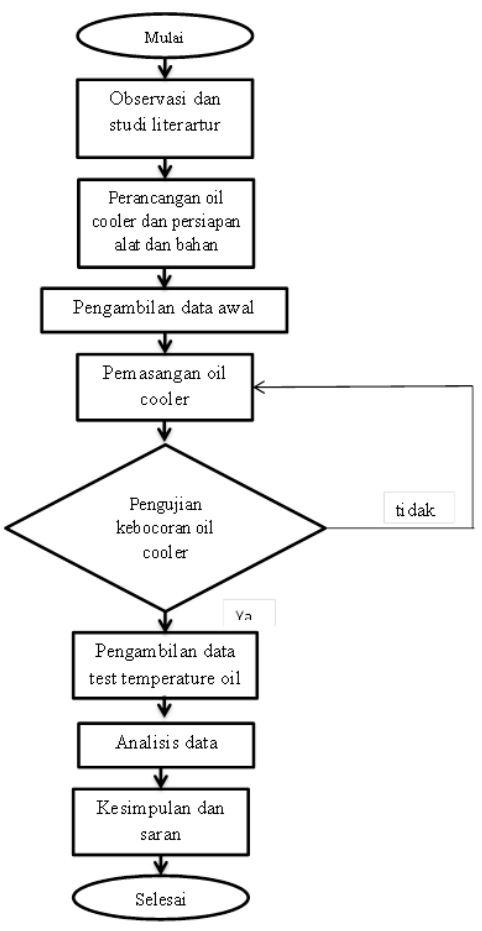

Gambar 2. Flowchart Penelitian

\section{HASIL DAN PEMBAHASAN}

\section{A. Desain Oil Cooler}

Pembuatan design adapter oil cooler penulis disini menggunakan software solidwork agar nanti memudahkan saat proses machining menggunakan CNC, sebelumnya penulis melakukan pengukuran agar mengetahui ukuran yang presisi dan adapter oil cooler bisa benarbenar digunakan.

Kemudian penulis melakukan pemilihan bahan untuk adapter oil cooler yang akan dibuat, penulis disini memilih bahan durallium karena durallium sangat mudah untuk di proses mesin. Fungsi adapter oil cooler disini adalah sebagai jalur pemisah yang akan ditempatkan di bak filter oli mesin sehingga tidak akan merubah konstruksi mesin. Karena penulis disini menginginkan membuat oil cooler pada mesin Kawasaki Dtracker 150 tanpa mengebor atau melubangi blok mesin.

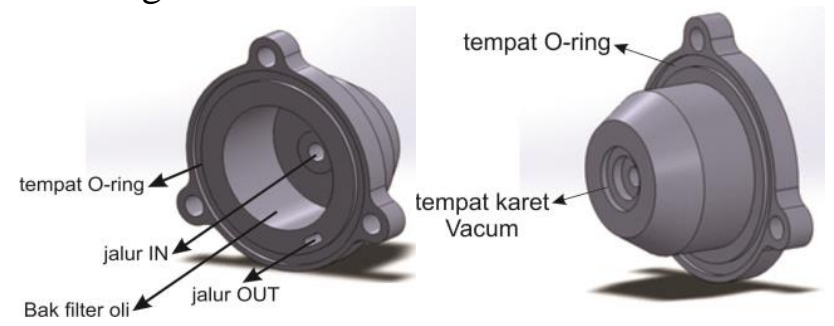

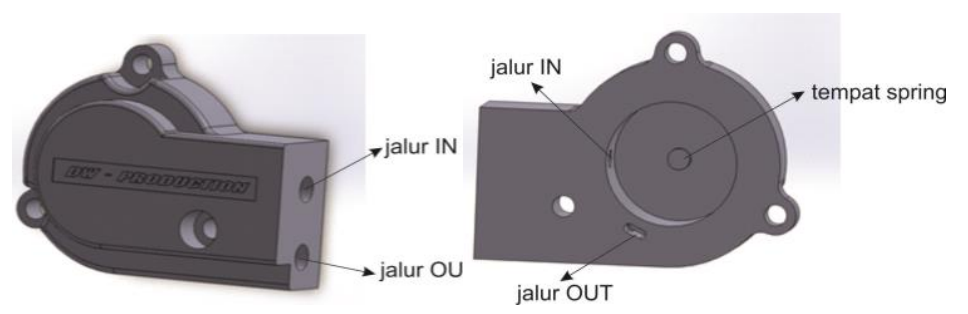

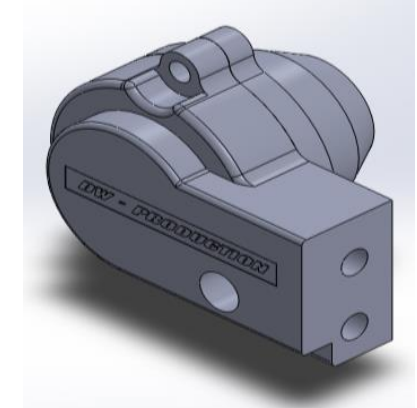

Gambar 3. Desain Oil Cooler

\section{B. Pemasangan Oil Cooler}

Pembuatan jalur in dan out oil cooler diambil pada bagian bak kopling lebih tepatnya pada bak filter oli. Alasan penulis mengapa memilih bak kopling sebagai jalur in dan out pada oil cooler karena penulis menginginkan tidak merubah konstruksi mesin, tidak melubangi, atau mengebor konstruksi mesin yang sudah ada, penulis hanya menambahkan sebuah komponen ke bak filter oli untuk merubah jalur oil yang sudah ada dan letak jalur utama oli yang dialirkan keseluruh komponen mesin terdapat pada bagian tersebut.

Secara otomatis oli dipompa terlebih dahulu kedalam in cooler dan keluar melalui lubang out cooler karena adanya gaya gravitasi. Selain itu jumlah oli yang didinginkan menjadi lebih banyak sehingga mesin menjadi lebih dingin. Perancangan jalur in oil cooler dengan cara memasang selang pada bagian dudukan dan dikencangkan dengan baut nepel. Lalu ujung selang selanjutnya dipasang di lubang in cooler.

\section{Pengaruh Temperatur Mesin}

Pengukuran temperatur panas mesin bertujuan untuk mengetahui perubahan suhu yang terjadi pada mesin setelah dibuatnya oil cooler untuk mesin Kawasaki Dtracker 150. 
Pengukuran tersebut menggunakan thermometer infrared sebagai alat pengukur temperatur mesin. Didalam pengukuran nanti penulis terlebih dahulu melakukan test uji kendaraan dengan jarak tempuh sejauh $20 \mathrm{Km}$, Kecepatan 50 $\mathrm{Km} / \mathrm{Jam}$, dan jenis lintasan jalan lurus.

Setelah itu penulis baru melakukan pengukuran temperatur dibagian cylinder head bagian depan, liner, di samping baut tap oli, dan bagian cooler. Setelah pengukuran temperatur sudah dilakukan, barulah dapat disimpulkan bahwa apakah pembuatan oil cooler pada sepeda motor Kawasaki Dtracker 150 benar - benar dapat mengurangi temperatur pada mesin motor tersebut atau tidak.

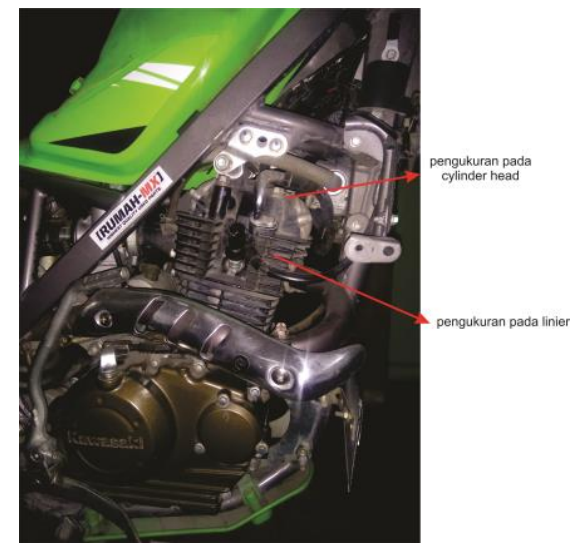

Gambar 4. letak pengukuran pada mesin.

Tabel 1. Temperatur sebelum dipasang oil cooler.

\begin{tabular}{|l|c|c|c|}
\hline $\begin{array}{c}\text { Posisi } \\
\text { Pengujian }\end{array}$ & $\begin{array}{c}\text { Temperatur } \\
\text { Awal }\end{array}$ & $\begin{array}{c}\text { Temperatur } \\
\text { Akhir }\end{array}$ & $\begin{array}{c}\text { Temperatur } \\
\text { Ruangan }\end{array}$ \\
\hline Head atas & $62,6^{\circ} \mathrm{C}$ & $115,7^{\circ} \mathrm{C}$ & $32^{\circ} \mathrm{C}$ \\
\hline Liner & $70,4^{\circ} \mathrm{C}$ & $136^{\circ} \mathrm{C}$ & $32^{\circ} \mathrm{C}$ \\
\hline Sebelah tap oli & $60,9^{\circ} \mathrm{C}$ & $105^{\circ} \mathrm{C}$ & $32^{\circ} \mathrm{C}$ \\
\hline
\end{tabular}

Note :

Temperatur Awal : temperatur awal saat mesin stasioner

Temperatur Akhir : temperatur akhir setelah pengujian

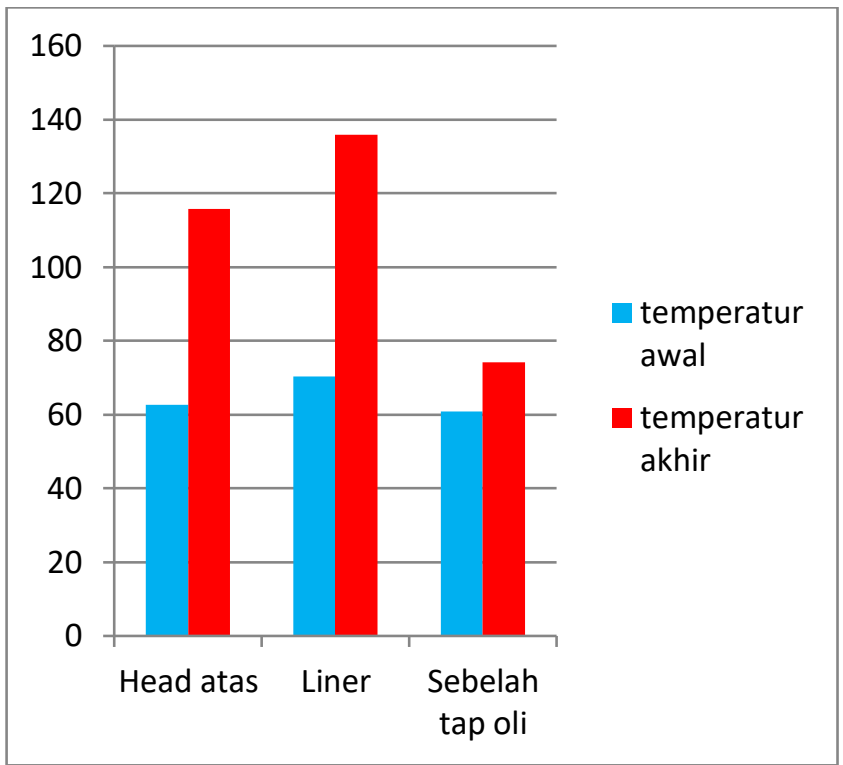

Gambar 5. Pengujian sebelum dipasang oil cooler.

Sebelum penulis melakukan pengujian terlebih dahulu mengukur temperatur sekitar terlebih dahulu dan di dapatkan suhu $32^{\circ} \mathrm{C}$ kemudian mesin didinginkan terlebih dahulu agar hasil pengukuran nanti benar - benar valid. Hasil temperatur awal yang didapatkan pada head atas $62,6^{\circ} \mathrm{C}$, pada liner $70,4^{\circ} \mathrm{C}$, dan di sebelah baut tap oli $60,9^{\circ} \mathrm{C}$. Kemudian dilakukan pengujian dengan cara memutari Kecamatan Banjarsari sebanyak 2 kali dengan waktu tempuh sekitar \pm 20 menit, dengan kecepatan $50 \mathrm{~km} / \mathrm{jam}$ pada waktu siang hari dapat disimpulkan sebelum dipasang sistem oil cooler temperatur mesin pada bagian head atas $115,7^{\circ} \mathrm{C}$, liner $136^{\circ} \mathrm{C}$, dan di sebelah baut tap oli $105^{\circ} \mathrm{C}$

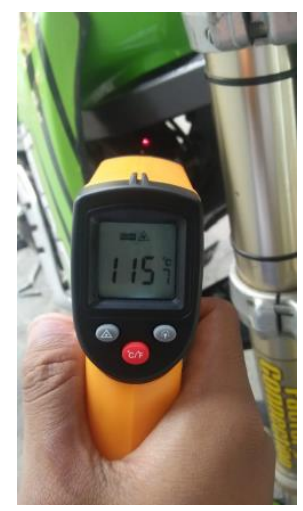

Gambar 6. Hasil pengukuran temperature mesin. 
Tabel 2 Temperatur sesudah dipasang oil cooler.

\begin{tabular}{|l|c|c|c|}
\hline $\begin{array}{c}\text { Posisi } \\
\text { Pengujian }\end{array}$ & $\begin{array}{c}\text { Temperatur } \\
\text { Awal }\end{array}$ & $\begin{array}{c}\text { Temperatur } \\
\text { Akhir }\end{array}$ & $\begin{array}{c}\text { Temperatur } \\
\text { Ruangan }\end{array}$ \\
\hline Head atas & $67,6^{\circ} \mathrm{C}$ & $88,9^{\circ} \mathrm{C}$ & $32^{\circ} \mathrm{C}$ \\
\hline Liner & $73,7^{\circ} \mathrm{C}$ & $113.3^{\circ} \mathrm{C}$ & $32^{\circ} \mathrm{C}$ \\
\hline Sebelah tap oli & $59,8^{\circ} \mathrm{C}$ & $74,3^{\circ} \mathrm{C}$ & $32^{\circ} \mathrm{C}$ \\
\hline Cooler & $37,7^{\circ} \mathrm{C}$ & $53,4^{\circ} \mathrm{C}$ & $32^{\circ} \mathrm{C}$ \\
\hline
\end{tabular}

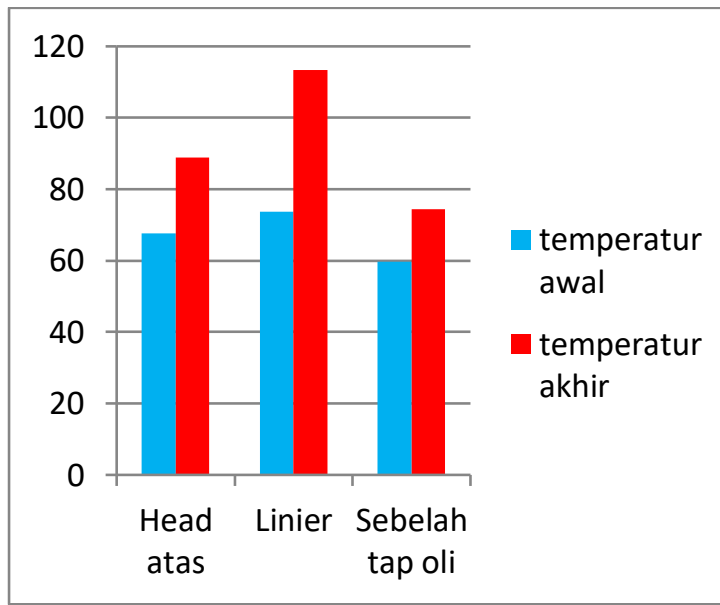

Gambar 7. grafik uji kondisi 1 sesudah dipasang oil cooler.

Sebelum penulis melakukan pengujian terlebih dahulu mengukur temperatur sekitar terlebih dahulu dan di dapatkan suhu $32^{\circ} \mathrm{C}$ kemudian mesin didinginkan terlebih dahulu agar hasil pengukuran nanti benar - benar valid. Hasil temperatur awal yang didapatkan pada head atas $67,6^{\circ} \mathrm{C}$, pada liner $73,7^{\circ} \mathrm{C}$, pada sebelah tap oli $59,8^{\circ} \mathrm{C}$, dan bagian cooler $37,7^{\circ} \mathrm{C}$. Kemudian dilakukan pengujian dengan cara memutari Kecamatan Banjarsari sebanyak 2 kali dengan waktu tempuh sekitar \pm 20 menit, dengan kecepatan $50 \mathrm{~km} / \mathrm{jam}$ pada waktu siang hari dapat disimpulkan sesudah dipasang sistem oil cooler temperatur mesin menurun pada bagian head atas $88,9^{\circ} \mathrm{C}$, liner $113.3^{\circ} \mathrm{C}$, di sebelah baut tap oli $74,3^{\circ} \mathrm{C}$, dan bagian cooler $53,4^{\circ} \mathrm{C}$

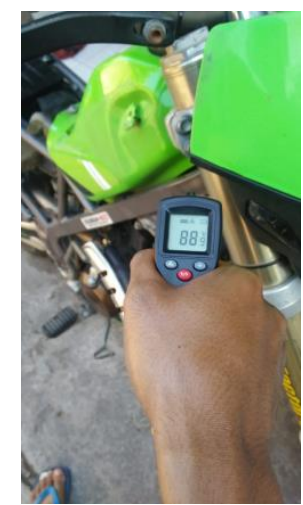
mesin.

Gambar 8. Hasil pengukuran temperature

Tabel 3 perbandingan sebelum dan sesudah di pasang oil cooler saat di kondisi 1.

\begin{tabular}{|l|c|c|c|}
\hline $\begin{array}{c}\text { Posisi } \\
\text { pengukuran }\end{array}$ & $\begin{array}{c}\text { Sebelum } \\
\text { dipasang }\end{array}$ & $\begin{array}{c}\text { Sesudah } \\
\text { dipasang }\end{array}$ & $\begin{array}{c}\text { Presentase } \\
\text { penurunan }\end{array}$ \\
\hline Head atas & $115,7^{\circ} \mathrm{C}$ & $88,9^{\circ} \mathrm{C}$ & $23 \%$ \\
\hline Liner & $136^{\circ} \mathrm{C}$ & $113.3^{\circ} \mathrm{C}$ & $17 \%$ \\
\hline Sebelah tap oli & $105^{\circ} \mathrm{C}$ & $74,3^{\circ} \mathrm{C}$ & $27 \%$ \\
\hline Cooler & - & $53,4^{\circ} \mathrm{C}$ & - \\
\hline
\end{tabular}

Rumus perhitungan presentase

$$
\begin{gathered}
=\frac{\text { Penurunan Temperatur }}{\text { Temperatur akhir sebelum dipasang oil cooler }} \times 100 \\
\text { dibagian head atas }=\frac{26,8^{\circ} \mathrm{C}}{115,7^{\circ} \mathrm{C}} \times 100=23 \% \\
\text { dibagian linier }=\frac{22,7^{\circ} \mathrm{C}}{136^{\circ} \mathrm{C}} \times 100=17 \% \\
\text { dibagian sebelah tap oli }=\frac{30,7^{\circ} \mathrm{C}}{105^{\circ} \mathrm{C}} \times 100=29 \%
\end{gathered}
$$

\section{KESIMPULAN}

1. Design air cooler yang cocok untuk motor Kawasaki D-Tracker menggunakan prinsip hidrolik tekanan oli dan dipasangkan di bagian bak kopling untuk memperoleh penerununan temperature yang maksimal

2. Terdapat penurunan temperature setelah pemasangan air cooler sebesar $23 \%$ pada blok mesin 


\section{DAFTAR PUSTAKA}

Akhmadi. N. A. dkk. (2016). Kinerja Sistem Pendingin Oli Pada Motor Diesel,

Hidayat. T. ST, M.Si. (2015). Modifikasi Sistem Pendingin (Sirip Dan Air) Pada Saluran Pelumas Sepeda Motor, UNU Surakarta. Fakultas Teknik : Tugas Akhir Diterbitkan

Jama. J. M.Ed. dkk. (2008). Teknik Sepeda Motor Jilid 3,Jakarta : Pusat Perbukuan Departemen Pendidikan Nasional

Politeknik Harapan Bersama Tegal. D3 Teknik Mesin : Tugas Akhir Diterbitkan.

Pribadi Sukma Wawan.(2017), Jurnal Analisis Sistem Pendingin Yamaha Vixion,Universitas Nusantara PGRI Kediri.Fakultas Teknik : Tugas Akhir Diterbitkan

S. Irfan. Ade. (2007), Analisis Sistem Pendingin Pada Mesin Isuzu Panther, Universitas Negeri Semarang. Fakultas Teknik : Tugas Akhir Diterbitkan

Saputra. B. A. S. (2017). Pengaruh Pengaplikasian Oil Cooler Terhadap Suhu Oli Dan Peforma Mesin Pada Kendaraan Sepeda Motor Mega Pro Tahun 2011, Universitas Negeri Surabaya. S1 Pendidikan Teknik Mesin. Fakultas Teknik : Tugas Akhir Diterbitkan.

Saputro. Y. S. (2016).Perancangan Oil Cooler Pada Mesin Honda GL MAX, Universitas Gajah Mada Yogyakarta. Departemen Teknik Mesin Sekolah Vokasi Universitas Gajah Mada : Tugas Akhir Tidak Diterbitkan.

Sudjarwo. (2013),Pemeliharaan Mesin Sepeda Motor.Malang : Vedc Malang.

https://oto.detik.com/tips-and-tricks-motor/d3116405/oil-cooler-menjaga-suhu-mesinmotor-untuk-touring-tetap-stabil

(diakses pada tanggal 27-08-2018 jam 18.30 WIB)

https://otomotifnet.gridoto.com/read/02210328/ harusnya-sangar-lah-kok-kawasaki-klx150-malah-centil?page=all

(diakses pada tanggal 27-08-2018 jam 18.30 WIB)

https://m.liputan6.com/otomotif/read/2841582/p asang-oil-cooler-kenapa-tidak (diakses pada tanggal 27-08-2018 jam 18.30 WIB) 